\title{
Public Provision of Private Goods and Equilibrium Unemployment*
}

\author{
Thomas Aronsson Mikael Markström and Tomas Sjögren \\ Department of Economics, Umea University, \\ SE - 90187 Umea, Sweden
}

March 2004

\begin{abstract}
This paper concerns public provision of a private good in a twotype model with optimal nonlinear income taxation. We assume that the wage rates are determined by bargaining between unions and firms, meaning that the equilibrium is characterized by unemployment. We show that, if the labor market is imperfectly competitive, additional mechanisms arise via the self-selection constraint, which may justify either more or less public provision of the private good than under perfect competition. Furthermore, public provision of private goods becomes a tool to influence the employment.

Keywords: Public provision of private goods, nonlinear taxation, unemployment

JEL classification: H21, H23, J51
\end{abstract}

${ }^{*}$ A research grant from FAS is gratefully acknowledged. 


\section{Introduction}

This paper deals with public provision of private goods under optimal nonlinear income taxation and imperfect competition in the labor market. The basic idea is to use insights from the literature on optimal taxation and provision of public goods under unemployment in order to learn more about how to use public provision of private goods for purposes of efficiency and redistribution. The analysis to be carried out in the paper relates to the selfselection approach to optimal taxation and is based on the two-type model developed by Stern (1982) and Stiglitz (1982).

There are several previous studies on optimal taxation and/or provision of public goods under unemployment. From our point of view, the most interesting part of the literature refers to the earlier studies dealing with nonlinear tax instruments. One issue in previous research is whether imperfect competition in the labor market may give rise to labor tax progression at the second best optimum ${ }^{1}$. Another is optimal redistribution via nonlinear taxation. In the context of a two-type model with union wage formation, Aronsson and Sjögren (2003) analyze the optimal use of income taxes, commodity taxes and public good provision. Their results imply that union wage formation gives rise to additional channels via which public policy affects the wage distribution and, therefore, the self-selection constraint. In addition, public policy becomes a tool to influence the employment, implying that the use of each policy instrument will be modified accordingly ${ }^{2}$.

\footnotetext{
${ }^{1}$ See e.g. Fuest and Huber (1997) and Aronsson and Sjögren (2004a, 2004b).

${ }^{2}$ The provision of public goods under unemployment has also been addressed in other contexts; see e.g. Andersen et al (1996) and Bovenberg and van den Ploeg (1996). Andersen et al. show that, even if the public good is pure waste, the governrment may still
} 
Previous studies on public provision of private goods assume competitive markets, where the decision to publicly provide private goods is explained in the context of optimal redistribution under asymmetric information ${ }^{3}$. The main part of the previous studies is also based on the assumption that the wage rates are exogenous. An important insight is that the role of publicly provided private goods depends on the structure of preferences. If the utility function is nonseparable, public provision of private goods will be welfare improving under certain conditions by relaxing the self-selection constraint. On the other hand, if leisure is weakly separable from the other goods in the utility function, it may not be possible to increase the welfare via public provision of private goods. Pirttilä and Tuomala (2002) extend the analysis by allowing the wage rates to be endogenous, as well as by assuming that the publicly provided private good gives rise to an external effect in the production. This means that the publicly provided private good affects the self-selection constraint via the wage distribution. One of their main contributions is to show that if the wage rates depend on the publicly provided quantity of a private good, then public provision of private goods may play a distinct role in the context of redistributive policy, even if leisure is weakly separable from the other goods in the utility function.

In this paper, we extend the analysis by assuming that the wage rates are determined by bargaining between unions and firms, implying that the equilibrium is characterized by unemployment. We show that additional choose to provide the public good, if it contributes to increase the employment. Bovenberg and van der Ploeg consider optimal proportional taxation and provision of public goods in an economy with environmental damage.

${ }^{3}$ See e.g. Blomquist and Christiansen (1995, 1998a and 1998b), Boadway and Marchand (1995) and Boadway et al. (1998). 
mechanisms arise via the self-selection constraint, which may justify either more or less public provision of the private good than under perfect competition. Furthermore, since public provision of a private good influences the employment, the paper also addresses employment-related motives behind publicly provided private goods.

The outline of the paper is as follows. In section 2, we present the model. Section 3 concerns public provision of a private good under optimal nonlinear income taxation. Section 4 summarizes the results.

\section{The Model}

We begin this section by considering the optimization problems of consumers and firms. We will then continue by describing the labor market.

\subsection{Consumers and Firms}

There are two types of consumers participating in the labor market; a lowability type (denoted by superindex 1 if employed) and a high-ability type (denoted by superindex 2 if employed). The distinction between ability-types refers to productivity, which is here interpreted to mean that the high-ability type faces a higher before tax wage rate than the low-ability type. Individuals have identical preferences defined by the utility function $u(c, h, q)$, where $c$ is a normal private good and $h$ leisure, whereas $q$ will be referred to as a 'quasi-private' good; it is a private good partly provided by the government. We characterize $q$ as follows; $q=g+z$, where $g$ is the amount provided by the government, and $z$ is purchased by the individual himself/herself. The government provides the same amount of the quasi-private good to all 
households, and it is assumed that $g$ cannot be resold. For simplicity, the prices of both goods are normalized to one. Leisure is defined as $h=H-l$, where $H$ is a time endowment and $l$ the hours of work. Finally, to simplify the analyses to be carried out below, we assume that $\lim _{c \rightarrow 0} u_{c}(c, h, q)=$ $\lim _{q \rightarrow 0} u_{q}(c, h, q) \rightarrow \infty$.

If employed, an individual of ability-type $i$ earns before tax labor income $w^{i} l^{i}$, where $w^{i}$ is the wage rate of ability-type $i$. The after tax income is denoted $B^{i}=w^{i} l^{i}-T\left(w^{i} l^{i}\right)$, in which $T(\cdot)$ is the tax function. Since the optimal tax and expenditure problem below will be formulated in terms of conditional indirect utility functions, it is convenient to start by solving the private optimization problem conditional on the hours of work. This means choosing $c^{i}$ and $z^{i}$ to maximize the utility conditional on $l^{i}$ and $g$ subject to the budget constraint $B^{i}=c^{i}+z^{i}$ and the nonnegativity constraint $z^{i} \geq 0$. Substituting the budget constraint into the utility function and maximizing with respect to $z^{i}$ gives the following Kuhn-Tucker conditions;

$$
u_{q}^{i}-u_{c}^{i} \leqslant 0 ; \quad z^{i}\left(u_{q}^{i}-u_{c}^{i}\right)=0
$$

where $u^{i}=u\left(c^{i}, h^{i}, q^{i}\right)$, while the subindices denote partial derivatives. If the nonnegativity constraint does not bind, equation (1) implicitly defines the conditional demand functions, $z^{i}=z\left(B^{i}, h^{i}, g\right)$ and $c^{i}=B^{i}-z\left(B^{i}, h^{i}, g\right)$. The conditional indirect utility function is written

$$
v^{i}=v\left(B^{i}, h^{i}, g\right)=u\left(B^{i}-z\left(B^{i}, h^{i}, g\right), h^{i}, g+z\left(B^{i}, h^{i}, g\right)\right)
$$

and satisfies the properties

$$
v_{B}^{i}=u_{c}^{i}, \quad v_{h}^{i}=u_{h}^{i}, \quad v_{g}^{i}=u_{g}^{i}=u_{q}^{i}
$$


With the conditional indirect utility function at our disposal, we can derive the hours of work by maximizing the conditional indirect utility function with respect to $l^{i}$ subject to the budget constraint $B^{i}=w^{i} l^{i}-T\left(w^{i} l^{i}\right)$. The first order condition for the hours of work is given by

$$
\frac{v_{h}^{i}}{v_{B}^{i}}=w^{i}\left(1-T_{y}^{i}\right)
$$

where $T_{y}^{i}=\partial T\left(y^{i}\right) / \partial y^{i}$ is the marginal income tax rate and $y^{i}=w^{i} l^{i}$. Conditional on the tax schedule, equation (4) implicitly defines the hours of work as a function of the wage rate and the publicly provided quantity of the quasi-private good, i.e. $l^{i}=l\left(w^{i}, g\right)$.

If unemployed, on the other hand, the individual receives a fixed tax-free benefit, $b$. The budget constraint becomes $b=c^{u}+z^{u}$, where the superindex " $u$ " refers to 'unemployed'. By analogy to the analysis carried out above, the conditional indirect utility function is written

$$
v^{u}=v(b, H, g)=u(b-z(b, H, g), H, g+z(b, H, g))
$$

Since individuals have identical preferences, equation (5) applies to unemployed individuals of both ability-types.

Since the technology is characterized by decreasing returns to scale (see below), there will be pure profits in the equilibrium. Therefore, following previous studies on optimal taxation under union wage setting, such as Fuest and Huber (1997) and Aronsson and Sjögren (2004a, 2004b), we introduce a second category of consumers, which is called 'firm-owners'4 . To simplify the

\footnotetext{
${ }^{4}$ The firm-owner type is interpreted as the owners of any fixed production factor. Instead of introducing the firm-owners, another alternative would have been to assume that the profit income is equally distributed among workers. It is not of importance for the
} 
analysis, we assume that the firm-owners do not work, implying that their only source of income is profits from the production. Since the number of firm-owners is not important in the analysis below, it will be normalized to one. The budget constraint of the firm-owner is given by $B^{0}=(1-s) \pi=$ $c^{0}+z^{0}$, where $\pi$ is the profit income and $s$ the profit income tax rate, while the superindex " 0 " is used to denote the firm-owner type. The indirect utility function becomes

$$
v^{0}=v\left(B^{0}, H, g\right)=u\left(B^{0}-z\left(B^{0}, H, g\right), H, g+z\left(B^{0}, H, g\right)\right)
$$

Turning to the production side of the economy, identical firms use the same technology to produce both goods in the economy. Since the number of firms is not important in the analysis, it will be normalized to one. The production function is written $F\left(L^{1}, L^{2}\right)$, where $L^{i}$ is total employment of ability-type $i$ measured as the number of employed persons, $N^{i}$, times the hours of work per employee, $l^{i}$. The function $F(\cdot)$ is characterized by decreasing returns to scale. Both inputs are essential, and the two abilitytypes are imperfect substitutes in production. Profit maximization implicitly defines a labor demand function for each ability-type, $L^{i}=L^{i}\left(w^{1}, w^{2}\right)$. Dividing by the hours of work per employee, we can write each labor demand function in terms of the number of employed persons; $N^{i}=\tilde{N}^{i}\left(w^{1}, w^{2}, l^{i}\right)=$ $L^{i}\left(w^{1}, w^{2}\right) / l^{i}$ for $i=1,2$. The profit function is written $\pi=\pi\left(w^{1}, w^{2}\right)$.

qualitative results derived below which option is chosen. Introducing a firm-owner type is slightly more convenient from a computational point of view than the other alternative. 


\subsection{The Labor Market}

There are $M^{i}$ individuals of ability-type $i$, which are organized by an abilitytype specific trade union $^{5}$. We assume that wage setting is decentralized in the sense that the unions treat the policy variables of the government as exogenous. By analogy to the treatment of the production sector, the number of unions facing each ability-type will be normalized to one. Each union acts as a Nash competitor towards the firm and towards the other union.

At present, there seems to be no standard approach for specifying the objective function of a union ${ }^{6}$. Following Oswald (1993), we assume that the union members of each ability-type can be ranked according to (exogenous) seniority rules, meaning that there is a known lay-off ordering within each union $^{7}$. Decisions within each union are taken by a majority vote, implying

\footnotetext{
${ }^{5}$ In practice, union membership may reflect several factors such as ability, industry and occupation. We have chosen to organize the individuals on the basis of their abilities, since we do not distinguish between different parts of the production sector. Another possibility is to assume that both ability-types are organized by the same union. As long as the wage rates reflect ability, the description of how the individuals are organized into unions does not affect the results to be derived below.

${ }^{6}$ See Kaufman (2001) for an overview of models of union wage setting.

${ }^{7}$ There is also a more formal argument behind our choice of labor market model; namely, that we would like to provide a framework suitable for studying public provision of private goods under unemployment. This rules out a description of the labor market, where the government via the tax system effectively controls all channels through which the wage rates influence the number of employed persons. One such model is the commonly applied expected utility framework with endogenous labor supply, in which the union recognizes how the hours of work respond to an increase in the wage rate. Aronsson and Sjögren (2004a) show that, if the objective function facing the union takes the expected utility form, a government that has access to a general income tax (as well as is able to redistribute income across all consumer types) will be able to implement full employment. The reason
} 
that the union member with median seniority is decisive. As a consequence, if the majority of union members are not at an immediate risk of becoming unemployed (which we assume here), the union is locally indifferent to the level of employment. The objective of the union will be the objective function facing the majority of its members; $u^{i}=u\left(c^{i}, h^{i}, q^{i}\right)$.

The wage rate of ability-type $i$ is determined by bargaining between union $i$ and the firm in the context of the right-to-manage framework. If the parties fail to reach an agreement, all union members become unemployed and receive the fall-back utility, $v^{u}=v(b, H, g)$, which is exogenous to the union by the assumption of decentralized wage formation, whereas the fall-back profit is zero. The outcome of the bargain for ability-type $i$ will be the wage rate that maximizes the Nash product

$$
\Omega^{i}=\left[v^{i}-v^{u}\right]^{a^{i}}[\pi(1-s)]^{1-a^{i}}
$$

subject to

$$
\begin{aligned}
B^{i} & =w^{i} l^{i}-T\left(w^{i} l^{i}\right) \\
l^{i} & =l\left(w^{i}, g\right)
\end{aligned}
$$

where $a^{i}$ is the bargaining power of union $i$. The first order condition can be simplified to read

$$
v_{B}^{i}\left(1-T_{y}^{i}\right) \pi-N^{i}\left[v^{i}-v^{u}\right]=0
$$

The second order condition is assumed to be fulfilled.

is that the general income tax becomes a perfect instrument to control the number of employed persons via the wage rate. 
Since the optimal tax and expenditure problem below will be formulated such that $B^{i}$ and $l^{i}$, instead of the parameters of the labor income tax function, constitute the direct decision variables, it will be convenient to rewrite equation (10) in order to eliminate $1-T_{y}^{i}$. This is done by using $v_{B}^{i}\left(1-T_{y}^{i}\right)=v_{h}^{i} / w^{i}$ from equation (4). By observing that $v^{i}$ is a function of $B^{i}, l^{i}$ and $g$, while $v^{u}$ is a function of $b$, and $g$, it is possible to write the bargained wage rate for ability-type $i$ as a function of $B^{i}, l^{i}, b, g$ and $w^{j}$ for $j \neq i$. Then, by combining the resulting wage equations for the two ability-types, we can derive a reduced form equation for $w^{i}$

$$
w^{i}=w^{i}\left(B^{1}, B^{2}, l^{1}, l^{2}, b, g\right)
$$

for $i=1,2$. Substituting into the labor demand functions, we obtain reduced form equations for the number of employed persons of each ability-type;

$$
N^{i}=N^{i}\left(B^{1}, B^{2}, l^{1}, l^{2}, b, g\right)
$$

for $i=1,2$.

\section{Public Provision of the Quasi-private Good}

Let us begin by solving the optimal tax and expenditure problem conditional on the publicly provided quantity of the quasi-private good. The government is assumed to implement a Pareto efficient policy in the sense of maximizing the utility of the employed low-ability type subject to minimum utility restrictions for the employed high-ability type, the unemployed and the firmowner, respectively. The set of policy instruments consists of the parameters of the income tax function, $T(\cdot)$, the profit income tax rate, $s$, the unem- 
ployment income, $b$, and the public provision of the quasi-private good, $g$ (which is held constant to begin with).

Note that, by choosing the parameters of the income tax function, the government can induce any desired combination of consumption and work hours for each ability-type, implying that $\left(B^{1}, l^{1}, B^{2}, l^{2}\right)$ and the parameters of the income tax function constitute two equivalent sets of policy instruments. It is, therefore, convenient to formulate the optimization problem such that the government directly chooses $B^{1}, l^{1}, B^{2}$ and $l^{2}$. Similarly, we use the consumption of the firm-owner, instead of the profit income tax rate, as a direct policy instrument. By using the private budget constraints and the objective function of the firm, it is straightforward to show that the budget constraint of the government can be written as

$$
F(\cdot)-\sum_{i=1}^{2} N^{i} B^{i}-\sum_{i=1}^{2}\left(M^{i}-N^{i}\right) b-B^{0}-\left(M^{1}+M^{2}+1\right) g=0
$$

where $F(\cdot)=F\left(L^{1}, L^{2}\right)$ depends on $B^{1}, l^{1}, B^{2}, l^{2}, b$ and $g$ via equations (12).

The informational assumptions in this paper are standard and imply that the government can observe the income of all individuals, although it cannot observe ability. Following most previous studies on optimal nonlinear taxation, we assume that the aim of the redistributive policy is to redistribute from high income earners to low income earners. As a consequence, we would like to avoid that the high-ability type wants to pretend to be a low-ability type. The hours of work that the high-ability needs to supply in order to reach the same income as the low ability type is given by

$$
\hat{l}^{2}=\frac{w^{1}\left(B^{1}, B^{2}, l^{1}, l^{2}, b, g\right)}{w^{2}\left(B^{1}, B^{2}, l^{1}, l^{2}, b, g\right)} l^{1}=\phi l^{1}
$$


where $\phi=w^{1} / w^{2}$ is the wage ratio. The self-selection constraint that may become binding can then be written as

$$
v^{2}=v\left(B^{2}, h^{2}, g\right) \geq v\left(B^{1}, H-\phi l^{1}, g\right)=\hat{v}^{2}
$$

where $\hat{v}^{2}$ denotes the utility of the mimicker. The Lagrangean corresponding to the optimal tax and expenditure problem becomes

$$
\begin{aligned}
\mathcal{L}= & v^{1}+\mu\left[v^{2}-\bar{v}^{2}\right]+\beta\left[v^{u}-\bar{v}^{u}\right]+\rho\left[v^{0}-\bar{v}^{0}\right]+\lambda\left[v^{2}-\hat{v}^{2}\right] \\
& +\gamma\left[F(\cdot)-\sum_{i=1}^{2} N^{i} B^{i}-\sum_{i=1}^{2}\left(M^{i}-N^{i}\right) b-B^{0}-\left(M^{1}+M^{2}+1\right) g\right]
\end{aligned}
$$

where $w^{i}$ and $N^{i}$ satisfy equations (11) and (12), respectively, while $\beta, \rho, \lambda$ and $\gamma$ are Lagrange multipliers. The first order conditions for $B^{1}, l^{1}, B^{2}, l^{2}$, $b$ and $B^{0}$ can be written

$$
\begin{aligned}
B^{1} & : \quad v_{B}^{1}=\lambda \hat{v}_{B}^{2}-\lambda \hat{v}_{h}^{2} \frac{\partial \phi}{\partial B^{1}} l^{1}+\gamma\left(N^{1}-\eta_{B}^{1}\right) \\
l^{1} & : \quad v_{h}^{1}=\lambda \hat{v}_{h}^{2}\left(\phi+\frac{\partial \phi}{\partial l^{1}} l^{1}\right)+\gamma\left(w^{1} N^{1}+\eta_{l}^{1}\right) \\
B^{2} & : \quad(\mu+\lambda) v_{B}^{2}=-\lambda \hat{v}_{h}^{2} \frac{\partial \phi}{\partial B^{2}} l^{1}+\gamma\left(N^{2}-\eta_{B}^{2}\right) \\
l^{2} & : \quad(\mu+\lambda) v_{h}^{2}=\lambda \hat{v}_{h}^{2} \frac{\partial \phi}{\partial l^{2}} l^{1}+\gamma\left(w^{2} N^{2}+\eta_{l}^{2}\right) \\
b & : \quad \beta v_{b}^{u}=-\lambda \hat{v}_{h}^{2} l^{1} \frac{\partial \phi}{\partial b}+\gamma\left(U-\eta_{b}\right) \\
B^{0} & : \quad \rho v_{B}^{0}=\gamma
\end{aligned}
$$

where

$$
\eta_{B}^{1}=\sum_{i=1}^{2}\left(b+T^{i}\right) \frac{\partial N^{i}}{\partial B^{1}}, \quad \eta_{l}^{1}=\sum_{i=1}^{2}\left(b+T^{i}\right) \frac{\partial N^{i}}{\partial l^{1}}
$$




$$
\begin{aligned}
\eta_{B}^{2}=\sum_{i=1}^{2}\left(b+T^{i}\right) \frac{\partial N^{i}}{\partial B^{2}}, & \eta_{l}^{2}=\sum_{i=1}^{2}\left(b+T^{i}\right) \frac{\partial N^{i}}{\partial l^{2}} \\
\eta_{b}=\sum_{i=1}^{2}\left(b+T^{i}\right) \frac{\partial N^{i}}{\partial b}, & U=\sum_{i=1}^{2}\left(M^{i}-N^{i}\right)
\end{aligned}
$$

and the subindices denote partial derivatives. The marginal income tax rates for the two ability-types implicit in equations (16) - (19), as well as the determinants of the unemployment benefit, have been characterized by Aronsson and Sjögren (2003) and will not be further discussed here.

Given that the tax and expenditure structure obeys equations (16) - (21), the welfare effect of increased public provision of the quasi-private good is given by

$$
\begin{aligned}
\frac{d \mathcal{L}}{d g}= & v_{g}^{1}+(\mu+\lambda) v_{g}^{2}+\beta v_{g}^{u}-\lambda \hat{v}_{g}^{2}+\rho v_{g}^{0}+\lambda \hat{v}_{h}^{2} \frac{\partial \phi}{\partial g} l^{1} \\
& +\gamma\left[\eta_{g}-\sum_{i=1}^{2} M^{i}-1\right]
\end{aligned}
$$

where

$$
\eta_{g}=\sum_{i=1}^{2}\left(b+T^{i}\right) \frac{\partial N^{i}}{\partial g}
$$

Now, by using equation (22) together with equations (16), (18), (20) and (21), we can derive the following result; 
Proposition 1 Within the given framework, the welfare effect of an increase in the public provision of the quasi-private good is given by

$$
\begin{aligned}
\frac{d £}{d g}= & {\left[v_{g}^{1}-v_{B}^{1}\right]+(\mu+\lambda)\left[v_{g}^{2}-v_{B}^{2}\right]+\rho\left[v_{g}^{0}-\bar{v}_{B}^{0}\right]-\lambda\left[\hat{v}_{g}^{2}-\hat{v}_{B}^{2}\right] } \\
& +\beta\left[v_{g}^{u}-v_{b}^{u}\right]+\lambda \hat{v}_{h}^{2} l^{1} \Phi+\gamma \eta
\end{aligned}
$$

where

$$
\begin{aligned}
\Phi & =\frac{\partial \phi}{\partial g}-\frac{\partial \phi}{\partial B^{1}}-\frac{\partial \phi}{\partial B^{2}}-\frac{\partial \phi}{\partial b} \\
\eta & =\eta_{g}-\eta_{B}^{1}-\eta_{B}^{2}-\eta_{b}
\end{aligned}
$$

To interpret Proposition 1, consider first the special case with exogenous wage rates and perfect competition in the labor market. Equation (23) then simplifies to read

$$
\frac{d £}{d g}=\left[v_{g}^{1}-v_{B}^{1}\right]+(\mu+\lambda)\left[v_{g}^{2}-v_{B}^{2}\right]+\rho\left[v_{g}^{0}-\bar{v}_{B}^{0}\right]-\lambda\left[\hat{v}_{g}^{2}-\hat{v}_{B}^{2}\right]
$$

Except for the term $\rho\left[v_{g}^{0}-\bar{v}_{B}^{0}\right]$, which is associated with the firm-owner, equation (24) is a restatement of a result derived by Boadway and Marchand (1995). Note first that if $z^{0}>0, z^{1}>0, z^{2}>0$ and $\hat{z}^{2}>0$ at the (conditional) second best optimum, then the welfare effect of a small increase in $g$ is zero. However, as $g$ continues to increase, the private provision of the quasi-private good will be reduced and eventually go to zero. Therefore, it is clear that public provision of the quasi-private good can be used to increase the welfare, if the mimicker becomes crowded out, whereas the true ability-types do not become crowded out. In this case, the first three terms on the right hand side of equation (24) are equal to zero, whereas the fourth 
term is positive. The intuition is that increasing $g$ above the point where the mimicker becomes crowded out relaxes the self-selection constraint.

Returning to the more general case with endogenous wage rates and unemployment, several additional mechanisms arise via which public provision of the quasi-private good affects welfare. Note first that an increase in $g$ affects the wage rates and, therefore, the self-selection constraint via the wage ratio. This has been pointed out by Pirttilä and Tuomala (2002), although the mechanism discussed in their study is an external effect in the production instead of union wage formation. In either case, however, the intuition is that if $\partial \phi / \partial g>0(<0)$, then public provision of the quasi-private good increases (decreases) the wage ratio which, in turn, makes mimicking less (more) attractive. As such, this effect contributes to increase (decrease) $g$.

The remaining terms in the second row of equation (23) have, to our knowledge, not been addressed in previous studies. By analogy to the first three terms in the first row, the second row of equation (23) contains the expression $\beta\left[v_{g}^{u}-v_{b}^{u}\right]$, which follows because an increase in the public provision of the quasi-private good affects the utility of the unemployed. More importantly, however, public provision of the quasi-private good also becomes a tool for influencing the number of employed persons. This so called 'employment effect' is measured by $\eta_{g}$. An increase in the number of employed persons increases the tax revenues net of transfer payments, implying that the public expenditures become less costly to finance. To be more specific, each additional employee of ability-type $i$ gives rise to an increase in the tax revenues net of transfer payments equal to $T^{i}+b$, which determines the welfare contribution of an increase in $N^{i}$. Therefore, if an increase in the public provision of the quasi-private good increases (decreases) the number of em- 
ployed persons, so $\eta_{g}>0(<0)$, the employment effect provides an additional incentive (disincentive) to publicly provide the quasi-private good.

Another interesting observation is that $g$ does not only have direct effects on the cost benefit rule: an increase in $g$ must be accompanied by an increase in the tax revenues which, in turn, decreases the income available for private consumption, i.e. $B^{1}, B^{2}$ and $b$. According to equation (23), $B^{1}, B^{2}$ and $b$ affect the cost benefit rule for $g$ via two channels; (i) the wage ratio and (ii) the number of employed persons. These effects are absent in previous studies, which are based on the assumption of perfectly competitive labor markets. The reason is that, if the labor market is competitive, $b=0$ while $B^{1}$ and $B^{2}$ neither affect the wage ratio $^{8}$ nor the number of employed persons. In an economy with union wage setting, on the other hand, a broader set of variables affect wage formation and, therefore, the wage ratio. For instance, if $\partial \phi / \partial B^{1}>0(<0)$, the decrease in private income associated with higher expenditures on $g$ will decrease (increase) the wage ratio. As such, mimicking becomes more (less) attractive, meaning that the government has an incentive to provide less (more) of the quasi-private good than it would otherwise have done. The effects of $B^{2}$ and $b$ on the wage ratio can be interpreted in a similar way. The other channel for $B^{1}, B^{2}$ and $b$ to affect the cost benefit rule comes from the relationship between private income and employment; here represented by $\eta_{B}^{1}, \eta_{B}^{2}$ and $\eta_{b}$. If $\eta_{B}^{1}>0(<0)$, the reduction in income

${ }^{8}$ Under perfect competition in the labor market, the wage ratio is defined as

$$
\phi=w^{1} / w^{2}=F_{L^{1}}\left(L^{1}, L^{2}\right) / F_{L^{2}}\left(L^{1}, L^{2}\right)
$$

where $L^{i}=M^{i} l^{i}$ and $M^{i}$ is a constant. This means that the effects of $l^{1}$ and $l^{2}$ fully capture the influence of taxation on the wage ratio. As we explained above, this property will no longer apply under union wage formation. 
available for private consumption of the low-ability type - following a higher $g$ - will contribute to decrease (increase) the number of employed persons. As a consequence, to avoid the decrease (stimulate an increase) in the number of employed persons, there is an incentive to publicly provide less (more) of the quasi-private good than under full employment. The other employment effects, $\eta_{B}^{2}$ and $\eta_{b}$, have similar interpretations.

Weak separability between leisure and the other goods in the utility function means that the mimicker and the low-ability type become crowded out at the same point. As a consequence, in the special case with fixed wage rates and perfect competition, it may not be possible to justify public provision of private goods. However, by relaxing either of these two assumptions, public provision of private goods will have a distinct role to play, even if leisure is weakly separable from the other goods. Pirttilä and Tuomala (2002) consider a model with endogenous wage rates. By abstracting from the direct productivity effect emphasized in their analysis, which is not relevant in our case where the quasi-private good only enters the utility function (and not the production function), their result implies that if leisure is weakly separable from the other goods, then it is welfare improving to publicly provide the quasi-private good if this contributes to reduce the wage differential, i.e. $\partial \phi / \partial g>0$. In our case, where the wage rates are determined by bargaining between unions and firms, we obtain the following result;

Proposition 2 If $\Phi+\eta>0$, it is possible to increase the welfare via public provision of the quasi-private good.

In other words, if the joint influence of $g, B^{1}, B^{2}$ and $b$ is to reduce the wage differential and/or to increase the number of employed persons, 
then public provision of the quasi-private is justified by arguments other than nonseparability. The reason is, of course, that private purchases of the quasi-private good neither recognizes the effects via the wage ratio nor the employment effects.

\section{Summary}

This paper concerns public provision of private goods under imperfect competition in the labor market. The analysis is based on a two-type model, where the wage rates are determined by bargaining between unions and firms. As a consequence, the equilibrium is characterized by unemployment. We would like to emphasize two aspects of publicly provided private goods. First, union wage setting gives rise to additional mechanisms via which the policy instruments affect the wage distribution. The reason is that the private income after tax of each employed ability-type as well as the unemployment benefit affect the wage ratio. Second, the fact that the equilibrium in our case may be characterized by unemployment implies that public provision of private goods can be used to affect the employment: both directly via the publicly provided quantity and indirectly via the necessity to raise additional tax revenues. Therefore, this paper points at a broader set of mechanisms behind public provision of private goods than previous studies.

\section{References}

[1] Andersen, T. M., Sandemann Rasmussen, B. and Sörensen, J. R. (1996) Optimal Fiscal Policy in Open Economies with Labor Market Distor- 
tions. Journal of Public Economics 63, 103-117.

[2] Aronsson, T. and Sjögren, T. (2003) Income Taxation, Commodity Taxation and Provision of Public Goods under Labor Market Imperfections. Finanzarchiv 59, 347-370.

[3] Aronsson, T. and Sjögren, T. (2004a) Is the Optimal Labor Income Tax Progressive in a Unionized Economy? Forthcoming in Scandinavian Journal of Economics.

[4] Aronsson, T. and Sjögren, T. (2004b) Efficient Taxation, Wage Bargaining and Policy Coordination. Forthcoming in Journal of Public Economics.

[5] Boadway, R. and Marchand, M. (1995) The use of Public Expenditures for Redistributive Purposes. Oxford Economic Papers 47, 45-59.

[6] Boadway, R., Marchand, M. and Sato, M. (1998) Subsidies versus Public Provision of Private Goods as Instruments for Redistribution. Scandinavian Journal of Economics 100, 545-564.

[7] Blomquist, S. and Christiansen, V. (1995) Public Provision of Private Goods as a Redistributive Device in an Optimum Income Tax Model. Scandinavian Journal of Economics 97, 547-567.

[8] Blomquist, S. and Christiansen, V. (1998a) Topping up or Opting out? The Optimal Design of Public Provision Schemes. International Economic Review 39, 399-411.

[9] Blomquist, S. and Christiansen, V. (1998b) Price Subsidies versus Public Provision. International Tax and Public Finance 5, 283-306. 
[10] Bovenberg, A.L. and van der Ploeg, F. (1996) Optimal Taxation, Public Goods and Environmental Policy with Involuntary Unemployment. Journal of Public Economics 62, 69-83.

[11] Fuest, C. and Huber, B. (1997) Wage Bargaining, Labor-tax Progression and Welfare. Journal of Economics 66, 127-150.

[12] Kaufman, B. Models of Union Wage Determination: What Have We Learned Since Dunlop and Ross? Industrial Relations 41, 110-158.

[13] Pirttilä, J. and Tuomala, M. (2002) Publicly Provided Private Goods and Redistribution: A General Equilibrium Analysis. Scandinavian Journal of Economics 104, 173-188.

[14] Stern, N.H. (1982) Optimum Taxation with Errors in Administration. Journal of Public Economics 17, 181-211.

[15] Stiglitz, J. E. (1982) Self-Selection and Pareto Efficient Taxation. Journal of Public Economics 17, 213-240. 